Escalante, L. La memoria como derecho humano en Argentina: Una reconstrucción desde la teoría crítica. Derecho y Ciencias Sociales. Mayo -Octubre 2021. № 25 .Pgs 1-22 ISSN 1852-2971. Instituto de Cultura Jurídica y Maestría en Sociología Jurídica. Facultad de Ciencias Jurídicas y Sociales. Universidad Nacional de La Plata. Argentina.

\title{
La memoria como derecho humano en Argentina: una reconstrucción desde la teorìa crítica
}

Memory as a human right in Argentina: a reconstruction based on critical theory

Lucía S. Escalante

\section{Resumen}

Para la teoría crítica de los derechos humanos, la memoria se ha convertido en un instrumento eficaz y necesario para visibilizar a las víctimas y condenar una parte de nuestra historia. La importancia de la memoria como derecho humano recae en su doble dimensión, actúa como reparación de las víctimas y sus familiares evitando el olvido que se traduce en impunidad, y como garantía de no repetición, ya que promueve la creación de una conciencia o memoria colectiva en aquellos países que transitan periodos de justicia transicional.

Sin embargo, el derecho humano a la memoria no ha sido reconocido explícitamente por la normativa y jurisprudencia internacional y nacional, como sí lo fue el derecho a la verdad íntimamente relacionado con el primero como se expone a lo largo del texto. En este trabajo se realizará una aproximación a su reconstrucción desde la teoría crítica asumida y, se indagarán las políticas públicas adoptadas en Argentina que permitan concluir el estado de reconocimiento del derecho a la memoria en el país. La metodología utilizada consiste en el análisis documental del material bibliográfico y normativo pertinente que permita definir conceptos y parámetros mediante el análisis de textos.

Palabras clave: memoria - derechos humanos - teoría crítica.

\begin{abstract}
For the critical theory of human rights, memory has become an effective and necessary instrument to make victims visible and condemn a part of our history. The importance of memory as a human right falls on its double dimension, it acts as reparation for victims and their families, avoiding forgetfulness that results in impunity, and as a guarantee of nonrepetition, since it promotes the creation of a collective conscience or memory in those countries that go through periods of transitional justice.

However, the Human Right to Memory has not been explicitly recognized by international and national regulations and jurisprudence, in contrast to the situation of the right to the truth -closely related to the first- and exposed throughout the text. Finally, in in this article we will reconstruct based on critical theory and the public policies adopted in Argentina will be investigated to conclude the status of recognition of the right to memory in the country. The methodology used consists of the documentary analysis of the pertinent bibliographic and normative material.
\end{abstract}

Keywords: memory - human rights - critical theory.

\footnotetext{
- Abogada. Becaria de Doctorado del CIN, Programa PERHID. Docente de la asignatura Derecho Político de la Facultad de Derecho (UNMdP). Integrante del grupo de investigación Pensamiento Crítico del CIDDH 'Alicia Moreau'. Correo: lucia_escalante@hotmail.com

Recibido: 20/12/2020 Publicable con correcciones: 12/7/2021

https://doi.org/10.24215/18522971e089
} 
Escalante, L. La memoria como derecho humano en Argentina: Una reconstrucción desde la teoría crítica. Derecho y Ciencias Sociales. Mayo -Octubre 2021. № 25 .Pgs 1-22 ISSN 1852-2971. Instituto de Cultura Jurídica y Maestría en Sociología Jurídica. Facultad de Ciencias Jurídicas y Sociales. Universidad Nacional de La Plata. Argentina.

\section{La memoria como derecho humano en Argentina: una reconstrucción desde la teorìa crítica}

Lucía S. Escalante

\section{Introducción}

Desde mediados del siglo pasado han proliferado los estudios en las ciencias sociales sobre la memoria colectiva ${ }^{1}$. Ello después del hito que marcara el Holocausto, que inauguró un periodo que ha estado signado por asesinatos masivos, masacres y genocidios, que han dejado secuelas en aquellos países que se han visto sometidos por gobiernos autoritarios, o que han sufrido períodos de violencia y restricción de las libertades fundamentales como es la Argentina.

Es así que al finalizar la II Guerra Mundial, en el marco de la consolidación del Derecho Internacional de los Derechos Humanos y del Derecho Internacional Humanitario, la comunidad internacional instó la creación de instrumentos para la lucha contra la impunidad bajo las premisas de verdad, justicia, reparación -que incluye las garantías de no repetición- y memoria; se define a esta última como un derecho humano fundamental y presupuesto para lograr la efectividad de los tres primeros ${ }^{2}$.

Desde una teoría critica de los derechos humanos, que los entiende como un movimiento social, político e intelectual, un fenómeno histórico de carácter emancipatorio, ampliamente exigibles y cuyo reconocimiento se afirma categóricamente (Arias Marín, 2015), la memoria se ha convertido en un instrumento eficaz y necesario para visibilizar y condenar una parte de nuestra historia.

Lisandro Cabrera Suarez (2012) conceptualiza a la memoria como "el derecho individual y colectivo, reconocido jurídicamente, que puede ser entendido como el derecho a entender y elaborar el pasado". El autor remarca la importancia de la memoria en el campo de la justicia, ya que "del conocimiento de la verdad del delito, su difusión pública y la preservación del recuerdo de la víctima, permite que la impunidad no se prolongue en el tiempo" (p. 175).

\footnotetext{
${ }^{1}$ El concepto de memoria colectiva fue acuñado por primera vez por Halbwachs (2004 [1968]) quien sostuvo como idea central que además del proceso de retención y de memoria individual vinculados con los procesos fisiológicos del cerebro de cada individuo, hay que suponer la existencia de una memoria social que preserva el saber sobre acontecimientos y valores dentro de un grupo. Sin perjuicio de lo cual, en el presente trabajo se destaca la existencia pluralidad de memorias, aun cuando se haga referencia a esta de forma individual, en tanto están en permanente construcción social, son procesos subjetivos, objeto de disputas y luchas de poder, que pueden resignificarse con el paso del tiempo (Guglielmucci, 2013; Jelin, 2012).

${ }^{2}$ La Comisión de Derechos Humanos de la ONU promulgó los principios contra la impunidad en 1997, a través del informe del relator especial Luis Joinet.
} 
Escalante, L. La memoria como derecho humano en Argentina: Una reconstrucción desde la teoría crítica. Derecho y Ciencias Sociales. Mayo -Octubre 2021. № 25 .Pgs 1-22 ISSN 1852-2971. Instituto de Cultura Jurídica y Maestría en Sociología Jurídica. Facultad de Ciencias Jurídicas y Sociales. Universidad Nacional de La Plata. Argentina.

Por otra parte, Felipe Gómez Isa (2006) refiere al derecho a la memoria en su dimensión individual como el derecho a ser recordado a los que se les negó esa posibilidad, pero también como un derecho colectivo de la comunidad de demandar por ese recuerdo de los que ya no existen.

Su importancia recae en una doble dimensión: actúa como 'reparación' de las víctimas y sus familiares evitando el olvido que se traduce en impunidad -dimensión individual-, y como 'garantía de no repetición', ya que promueve la creación de una conciencia o memoria colectiva en aquellos países que transitan periodos de justicia transicional ${ }^{3}$, es decir, de cambios políticos que surgen con posterioridad a situaciones de conflicto armado o de regímenes autoritarios cuando transitan hacia la paz o hacia la democracia -dimensión colectiva-.

La vertiente individual de este derecho es positiva porque cumple la función de reparación y restituye la dignidad a las víctimas mediante su visibilización, sin embargo debe estar acompañada por políticas públicas como parte de las obligaciones que tienen los Estados que garanticen también su dimensión colectiva mediante la recuperación de la memoria para toda la sociedad en contextos de construcción democrática ${ }^{4}$.

El pasado se transmite bajo la consigna de que podemos aprender de él, ésta idea "está implícita en el sentido común que guía la acción política de quienes proponen en relación a los crímenes cometidos por el aparato terrorista de la última dictadura argentina: "Recordar para no repetir" o "Nunca más"” (Jelin, 2012, p. 147).

Ahora bien, la memoria no ha sido reconocida explícitamente como derecho humano por la normativa y jurisprudencia internacional y nacional, por lo que en este trabajo se realizará una aproximación a su reconstrucción a través de esas fuentes. Asimismo, se indagarán las políticas públicas adoptadas en Argentina que permitan concluir el estado del reconocimiento de la memoria en la esfera del derecho (Honneth, 1997) en el país.

Intentaré responder a las siguientes preguntas: ¿Se puede reconstruir a la memoria como derecho humano a través de una indagación en la normativa y jurisprudencia internacional,

\footnotetext{
${ }^{3}$ El International Center for Transitional Justice define que "la justicia transicional es una respuesta a las violaciones sistemáticas o generalizadas de los derechos humanos, que por ser tan numerosas y graves el sistema de justicia normal no podría proporcionar una respuesta adecuada" ( $<$ www.ictj.org $>$ ).

${ }^{4}$ En este artículo se diferencia por una parte la noción de memoria individual que alude a los procesos mediante los cuales los sujetos se relacionan individualmente con su pasado y de memoria colectiva entendida como a las modalidades mediante las cuales una sociedad elabora y negocia sentidos colectivos sobre su pasado (Jelin, 2012) de las dimensiones individual (actúa como reconocimiento y reparación de las víctimas) y colectiva del derecho a la memoria (se encuentra entre las garantías de no repetición y colabora en la creación de una conciencia o memoria colectiva en los procesos de justicia transicional).
} 
Escalante, L. La memoria como derecho humano en Argentina: Una reconstrucción desde la teoría crítica. Derecho y Ciencias Sociales. Mayo -Octubre 2021. No 25 .Pgs 1-22 ISSN 1852-2971. Instituto de Cultura Jurídica y Maestría en Sociología Jurídica. Facultad de Ciencias Jurídicas y Sociales. Universidad Nacional de La Plata. Argentina.

regional y nacional sobre los otros pilares de la justicia transicional -derecho a la verdad, justicia y reparación que incluye las garantías de no repetición-? ¿Qué implica asumir un postulado de los derechos humanos desde una teoría crítica en esta reconstrucción? ¿Qué reconocimiento jurídico se le ha dado en el país al derecho a la memoria tanto en su dimensión individual como colectiva? No pretendo contestar estos interrogantes exhaustivamente en este trabajo, sino más bien ofrecer un recorrido que contribuya a definir algunos términos de las respuestas que colaboren en la vacancia del desarrollo de la memoria como derecho humano frente a la frondosa e importante producción existente en el campo de las ciencias sociales.

La metodología empleada fue el análisis de textos, se realizó un relevamiento y estudio exhaustivo de las normas y estándares nacionales e internacionales aplicables al objeto de estudio, así como de la bibliografía pertinente que permitió definir conceptos y parámetros.

\section{La memoria desde una teoría crítica de los derechos humanos}

La teoría crítica, que surge con los aportes de la Escuela de Frankfurt, y en la tradición del pensamiento de Marx, tiene como punto de partida la convicción de que es posible transformar las condiciones sociales de opresión y explotación de la realidad, en tanto son construcciones históricas y por ende también susceptibles de ser cambiadas.

Si bien el individuo suele aceptar naturalmente, como preestablecidas, las destinaciones básicas de su existencia, la teoría crítica relativiza esa aceptación y sostiene que las diferencias surgen del obrar humano, y por lo tanto pueden estar subordinadas a la decisión planificada (Horkheimer, 2003 [1974]). La sociedad resulta ser el producto de los hombres, dónde estos pueden reconocerse a ellos mismos y la transformación resulta posible (Adorno, 2001 [1972]).

En ese sentido, según Herrera Flores (2005) una teoría crítica en derechos humanos tiene como punto de partida el "convencimiento de que todo lo que social e individualmente somos está necesariamente sometido a la posibilidad de cambio y transformación" (p. 179) y, desempeña un papel de concienciación que favorezca la movilización y mantenga en alto los objetivos y metas trazados en la búsqueda de condiciones de vida digna (Herrera Flores, 2008). Esto debe ser matizado y contextualizado con el análisis materialista histórico y la comprensión de los condicionamientos que genera el grado de desarrollo alcanzado por la estructura económico social para las posibilidades del cambio.

Lejos de un enfoque estático, como explica Harvey (2007), la teoría critica emplea una visión holística que adopta una comprensión relacional y dialéctica de las cosas. De esta manera, entiende a la realidad como una totalidad, que no es un simple agregado de elementos 
Escalante, L. La memoria como derecho humano en Argentina: Una reconstrucción desde la teoría crítica. Derecho y Ciencias Sociales. Mayo -Octubre 2021. № 25 .Pgs 1-22 ISSN 1852-2971. Instituto de Cultura Jurídica y Maestría en Sociología Jurídica. Facultad de Ciencias Jurídicas y Sociales. Universidad Nacional de La Plata. Argentina.

ni tiene un significado independiente de sus componentes, sino más bien "una totalidad de partes internamente relacionadas, cada una de las cuales puede concebirse como una relación expandible, de forma que cada una en su plenitud puede representar a la totalidad" (p. 88). Desde el punto de vista ontológico, el método dialéctico relacional tiene por objeto investigar las relaciones entre el todo y las partes, para descubrir en sus contradicciones las leyes que rigen la transformación interna de una sociedad y conforme las cuales ella puede ser reestructurada.

Por otra parte, la teoría crítica de los derechos humanos, adopta una perspectiva de las víctimas que trata de pensar los derechos humanos y vivirlos desde una opción por las víctimas, en contra de las dinámicas de victimización (Dussel, 2006). Desde esta posición, la memoria se ha convertido en un aspecto decisivo y catalizador para la noción de víctima contemporánea, rescata una visibilidad de sentido y de interpretación de existencia de su sufrimiento que permite contribuir a la fundamentación del proyecto y el discurso de los derechos humanos (Arias Marín, 2012).

Su importancia recae según Arias Marín (2015) en que la relación entre violencia y dignidad vulnerada no es directa, sino que está mediada por la noción de víctima. Tanto la violencia como la dignidad humana vulnerada son perceptibles a partir de la vida dañada en las víctimas, cuyo registro radica en las narrativas del sufrimiento.

La perspectiva de las víctimas no es sólo una opción ética y política, es también un posicionamiento hermenéutico para comprender los procesos sociales donde están en juego los derechos humanos y que permite la formulación de un proyecto de dignidad con un amplio alcance y la búsqueda de una sociedad sin víctimas, que haya logrado erradicar toda forma de victimización (Gándara Carballido, 2019).

Finalmente, una teoría crítica de los derechos humanos tiene que tomar en consideración aquellos instrumentos necesarios para asegurar que los logros alcanzados a través de las diversas luchas populares se consoliden y cuyo contenido se desprende de los objetivos articulados por los movimientos sociales que proveen de "un conocimiento suficiente acerca de cuáles son las formas existentes de injusticia social" (Fraser, 2006, p. 102). Dentro de estos instrumentos encontramos los dispositivos jurídicos (normativa y jurisprudencia nacional e internacional que conformaran el marco jurídico) como así también las políticas públicas adoptadas por el Estado. Su relevamiento y análisis es importante en tanto permite conocer el uso que se está haciendo de ellos en los procesos de lucha por la dignidad, como así también permite ubicar el uso de los sistemas de protección en el marco más amplio de una estrategia política y sociocultural que contribuya al empoderamiento de la sociedad. 
Escalante, L. La memoria como derecho humano en Argentina: Una reconstrucción desde la teoría crítica. Derecho y Ciencias Sociales. Mayo -Octubre 2021. No 25 .Pgs 1-22 ISSN 1852-2971. Instituto de Cultura Jurídica y Maestría en Sociología Jurídica. Facultad de Ciencias Jurídicas y Sociales. Universidad Nacional de La Plata. Argentina.

Este conocimiento de los diferentes instrumentos vigentes queda comprendido en la teoría del reconocimiento de Axel Honneth (1997), específicamente en la esfera del reconocimiento del derecho que le corresponde al Estado y que presenta como posibles daños la desposesión de derechos, estafa y discriminación. El autor parte de la formulación de Hegel en cuanto el "reconocimiento del derecho siempre designa la específica constitución de las relaciones de derecho modernas cuya pretensión se extiende, por principio, a todos los hombres en tanto que seres iguales y libres" (p. 133).

\section{Los instrumentos internacionales y regionales que receptan el Derecho a la Memoria}

Diferentes aspectos del derecho a la memoria son regulados por fuentes específicas del derecho internacional y regional de los derechos humanos que se analizan en este apartado. Según Jorg Luther (2010):

“el derecho a la memoria se presenta como un derecho complejo, susceptible de ser articulado al menos bajo tres aspectos y significados jurídicos: 1 . el de la libertad individual interior de recordar u olvidar libremente cualquier cosa; 2. el de la libertad individual, que puede ejercerse también colectivamente, de recordar algo a otros mediante informaciones y; 3 . el del derecho individual o colectivo de ser recordado o no ser recordado a o por algo" (p. 46).

Ahora bien, el primer aspecto queda en el ámbito privado de cada sujeto que tiene la libertad de elegir qué recuerda y qué no, mientras que el segundo es aquel que permite visibilizar el recuerdo sobre un hecho o persona en particular y finalmente el último es aquel que se ocupa más de cerca de la memoria colectiva y supone para la ciudadanía deberes de memoria en cuanto a la reconstrucción del pasado. Interesan para esta investigación los últimos dos aspectos del derecho a la memoria en tanto tienen incidencia externa y, por lo tanto repercuten en las víctimas o en la sociedad en su conjunto.

En el ámbito internacional, la Comisión de Derechos Humanos de la ONU promulgó los 'Principios contra la impunidad', a través del informe del relator especial Luis Joinet de 1997 (E/CN.4/Sub.2/1997/20/Rev.1), en el que se tipificaron los derechos a la verdad, la justicia y la reparación, se hace énfasis en el derecho a la memoria como presupuesto para la efectividad de los tres primeros.

Estos principios fueron actualizados en el año 2005 por la experta independiente Diane Orentlicher (E/CN.4/2005/102/Add.1) y su estructura se divide en tres secciones: el derecho de las víctimas a saber, el derecho de las víctimas a la justicia y el derecho a obtener reparación. Además, suma a título preventivo una serie de medidas destinadas a garantizar la no reiteración de las violaciones. 
Escalante, L. La memoria como derecho humano en Argentina: Una reconstrucción desde la teoría crítica. Derecho y Ciencias Sociales. Mayo -Octubre 2021. No 25 .Pgs 1-22 ISSN 1852-2971. Instituto de Cultura Jurídica y Maestría en Sociología Jurídica. Facultad de Ciencias Jurídicas y Sociales. Universidad Nacional de La Plata. Argentina.

En primer lugar, los principios les reconocen a las víctimas y sus familiares el derecho inalienable a la verdad acerca de las circunstancias en que se cometieron las violaciones y, en caso de fallecimiento o desaparición, sobre la suerte que corrió la víctima (principios $\mathrm{n}^{\circ} 3$ conforme la redacción original y $\mathrm{n}^{\circ} 4$ del texto actualizado).

Pero este derecho no sólo pertenece a las víctimas directas e indirectas sino a toda la sociedad, por lo que genera como contrapartida un 'deber de recordar' y el derecho a la memoria en su dimensión colectiva. En este sentido, sostiene que cada pueblo tiene el derecho inalienable a conocer la verdad acerca de los acontecimientos sucedidos y las circunstancias y los motivos que llevaron, mediante la violación masiva y sistemática de los derechos humanos, a la perpetración de crímenes aberrantes. Concluye que el ejercicio pleno y efectivo del derecho a la verdad es esencial para evitar que en el futuro se repitan las violaciones (principio $\mathrm{n}^{\circ} 1$ conforme E/CN.4/Sub.2/1997/20/Rev.1 y principio $\mathrm{n}^{\circ} 2$ de E/CN.4/2005/102/Add.1).

Asimismo, agrega que el conocimiento por un pueblo de la historia de su opresión forma parte de su patrimonio y, por ello, se debe conservar mediante la adopción de medidas adecuadas en aras del deber de recordar que incumbe al Estado. Esas medidas tienen por objeto preservar del olvido a la memoria colectiva y evitar que surjan tesis revisionistas y negacionistas (principios $\mathrm{n}^{\circ} 2 \mathrm{y} \mathrm{n}^{\circ} 3$ conforme texto original y actualizado respectivamente).

En segundo lugar, se recepta el derecho a la justicia que conlleva como deberes del Estado realizar investigaciones rápidas, minuciosas, independientes e imparciales y adoptar las medidas apropiadas respecto de sus autores, especialmente en la esfera de la justicia penal, para que sean procesados, juzgados y condenados debidamente. En los procesos judiciales se les reconoce amplia participación jurídica a las víctimas, sus familiares y a toda persona u organización no gubernamental que tenga un interés legítimo, junto con la posibilidad de hacer valer sus derechos beneficiándose de un recurso equitativo y efectivo, que permita lograr que su opresor sea juzgado y obtener reparación (principios $\mathrm{n}^{\circ} 18$ del documento E/CN.4/Sub.2/1997/20/Rev.1 y n ${ }^{\circ} 19$ del E/CN.4/2005/102/Add.1).

Por último, interesan especialmente los principios elaborados en torno al derecho a obtener reparación, que deberá abarcar todos los daños y perjuicios sufridos por las víctimas y, comprende medidas de restitución, indemnización, rehabilitación y satisfacción según lo establece el derecho internacional (principios $\mathrm{n}^{\circ} \quad 36$ y 34 de los documentos E/CN.4/Sub.2/1997/20/Rev.1 y E/CN.4/2005/102/Add.1).

En su informe especial, el relator Joinet retomó la 'Estructura de principios y directivas fundamentales concernientes al derecho a reparación de las víctimas de violaciones flagrantes 
Escalante, L. La memoria como derecho humano en Argentina: Una reconstrucción desde la teoría crítica. Derecho y Ciencias Sociales. Mayo -Octubre 2021. No 25 .Pgs 1-22 ISSN 1852-2971. Instituto de Cultura Jurídica y Maestría en Sociología Jurídica. Facultad de Ciencias Jurídicas y Sociales. Universidad Nacional de La Plata. Argentina.

de los derechos humanos y del derecho humanitario' establecidos por M. Theo van Boven (E/CN.4/Sub.2/1996/17) y, clasificó en tres tipos las medidas comprendidas en este derecho: a) Medidas de restitución (tendientes a que la víctima pueda volver a la situación anterior a la violación); b) Medidas de indemnización (reparan el perjuicio psíquico y moral, así como la pérdida de una oportunidad, daños materiales, atentados a la reputación y gastos de asistencia jurídica); c) Medidas de readaptación (comprenden atención médica -psicológica y psiquiátrica-).

Pero también hace referencia a las medidas de satisfacción, que son enumeradas en el principio $\mathrm{n}^{\circ} 15$ de los principios y directrices elaborados por $\mathrm{M}$. Theo van Boven y se caracterizan como 'garantías de no repetición'. Conforme el informe del relator Joinet las medidas de reparación actúan en el plano individual de las víctimas, su resarcimiento debe ser integral, beneficiándose de un recurso eficaz y con procedimientos públicos aplicables. Asimismo, tienen incidencia a nivel colectivo por su carácter simbólico y facilitan el deber de recordar al grupo.

Es así que, conforme los principios analizados podemos concluir que las medidas adoptadas para dar cumplimiento al derecho de reparación tienen como presupuesto el derecho a la memoria, en tanto actúan en su dimensión individual en aquellas ocasiones que en concepto de reparación reconocen a las víctimas como tales y hacen visibles los hechos que padecieron, por lo que evita que la impunidad de sus perpetradores se prolongue en el tiempo. A su vez, colaboran en la dimensión colectiva del derecho a la memoria que procura garantizar que las violaciones masivas a los derechos humanos no se repitan y, dan a conocer en el marco del derecho a la verdad los hechos aberrantes del pasado que resultan ser patrimonio de la historia de cada pueblo.

La memoria se relaciona con los derechos a obtener verdad, justicia y reparación, en tanto en una primera fase se hace ineludible el deber al recuerdo y la necesidad que la rememoración se imponga públicamente conociéndose la verdad de lo acontecido. Sólo una vez que esto se ha obtenido, puede iniciarse procesos judiciales en el que se logre la condena de los implicados, para luego dar paso a las reparaciones por las violaciones a los derechos humanos. Se ha comprobado mediante los distintos ejemplos de los procesos transicionales de los países de Latinoamérica que "si no hay reconocimiento de los hechos, la justicia y la reparación no se logran" (Allier, 2015: 41).

Por otra parte, en el ámbito regional la Comisión Interamericana de Derechos Humanos (CIDH) elaboró los 'Principios sobre Políticas Públicas de Memoria en las Américas' mediante la resolución 3/2019. En esa oportunidad, elaboró directrices específicamente 
Escalante, L. La memoria como derecho humano en Argentina: Una reconstrucción desde la teoría crítica. Derecho y Ciencias Sociales. Mayo -Octubre 2021. No 25 .Pgs 1-22 ISSN 1852-2971. Instituto de Cultura Jurídica y Maestría en Sociología Jurídica. Facultad de Ciencias Jurídicas y Sociales. Universidad Nacional de La Plata. Argentina.

destinadas a las políticas públicas de memoria relacionadas con Sitios de Memoria y los Archivos.

En el Principio I se deja sentado que los Estados deben asegurar un 'abordaje integral de la memoria', entendido como la obligación de adoptar políticas públicas de memoria coordinadas con procesos de justicia y rendición de cuentas, que incluya la búsqueda de la verdad, el establecimiento de reparaciones y la no repetición de las graves violaciones a los derechos humanos.

Al igual que 'Los principios internacionales para la protección y la promoción de los Derechos Humanos, para la lucha contra la impunidad', los aquí analizados afirman que la memoria, como derecho humano, resulta ser presupuesto de otros derechos humanos -justicia, verdad y reparación- y como tales deben ser considerados en su universalidad, indivisibilidad e interdependencia.

Conforme los Principios sobre Políticas de Memoria en las Américas, las políticas de memoria por un lado visibilizan a las víctimas y su participación en el diseño, implementación y gestión de las mismas, logra generar un ámbito propicio para que estas puedan exponer sus puntos de vista, e informar al Estado sobre sus necesidades específicas (principio II), por lo que son medios de reparación en la dimensión individual del derecho a la memoria.

Pero al realizarse también iniciativas de difusión y sensibilización de toda la sociedad para que participen en la formulación de políticas de memoria, se promueve la formación de una memoria colectiva del grupo que podría actuar como garantía de no repetición de los hechos aberrantes del pasado (principio III), más aún si las iniciativas incluyen: la realización de actos públicos de reconocimiento de responsabilidad del Estado, incorporación de la educación en derechos humanos en todos los niveles curriculares, creación de un día nacional conmemorativo, instauración de señalizaciones en el espacio público, entre otras (principio IX).

\section{La jurisprudencia de la Corte Interamericana de Derechos Humanos}

La Corte Interamericana de Derechos Humanos (Corte IDH) hace referencia de forma expresa en sus sentencias a la memoria, pero sin dar pautas claras a las obligaciones que de ella emanan y siempre en relación con los otros tres pilares de la justicia transicional: verdad, justicia y reparación (Dulitzky, 2017). Es por eso que, el análisis del derecho a la memoria en sus sentencias estará relacionado a estas tres obligaciones del Estado en materia de violaciones de derechos humanos, se aclara previamente que no se realizará un relevamiento exhaustivo de todas ellas ya que excedería ampliamente el marco y los objetivos del presente artículo. 
Escalante, L. La memoria como derecho humano en Argentina: Una reconstrucción desde la teoría crítica. Derecho y Ciencias Sociales. Mayo -Octubre 2021. No 25 .Pgs 1-22 ISSN 1852-2971. Instituto de Cultura Jurídica y Maestría en Sociología Jurídica. Facultad de Ciencias Jurídicas y Sociales. Universidad Nacional de La Plata. Argentina.

En relación al rol que cumple la memoria relacionada a la justicia, la Corte IDH entiende que los procesos ante ella y sus sentencias juegan un papel importante en la preservación de la memoria:

"Dada la importancia que reviste para el presente caso el establecimiento de los hechos que generaron la responsabilidad estatal, a fin de preservar la memoria histórica y evitar que se repitan hechos similares y como una forma de reparación a las víctimas, en este capítulo la Corte establecerá los hechos del presente caso, con base en los hechos sometidos a conocimiento de la Corte por la Comisión y el reconocimiento de responsabilidad efectuado por el Estado, tomando en consideración el escrito de solicitudes y argumentos de las representantes, así como el acervo probatorio del caso"5.

Las decisiones judiciales de un Tribunal Internacional que es imparcial y que dejan en claro la responsabilidad estatal, visibilizan a las víctimas como titulares de derechos y al Estado como violador pero también garante de esos derechos, reducen las posibilidades de teorías revisionistas o negacionistas de los hechos ocurridos y cumplen un rol fundamental en la preservación de la memoria colectiva. Sin embargo, la reconstrucción de la memoria colectiva a través de sentencias de la Corte está limitada por las formas judiciales que limitan la admisión de la prueba, su valoración y descripción mediante tecnicismos legales o judiciales, quedando en algunos casos excluidos muchos elementos $\mathrm{y}$, los que son incluidos suelen ser descriptos de manera inaccesible para la sociedad en general tanto por el lenguaje utilizado como por la extensión de las sentencias de la Corte (Dulitzky, 2017).

Por otra parte, la Corte ha resaltado la conexión y relaciones entre verdad y memoria, en particular entre comisiones de la verdad y la memoria. Así, ha indicado que: en cumplimiento de sus obligaciones de garantizar el derecho a conocer la verdad, los Estados pueden establecer comisiones de la verdad, las que contribuyen a la construcción y preservación de la memoria histórica, el esclarecimiento de hechos y la determinación de responsabilidades institucionales, sociales y políticas en determinados periodos históricos de una sociedad ${ }^{6}$. Se ha aceptado que en ciertas circunstancias, el nombre de los victimarios podría no ser divulgado en los informes de las comisiones de la verdad. Algo que obviamente no puede ser eliminado ni de la memoria social o individual.

Finalmente, la Corte IDH ha profundizado en mayor medida en la memoria como consecuencia de la reparación, aunque como lo hizo en el área de justicia y verdad no se refirió explícitamente a la existencia de un derecho-deber de memoria.

\footnotetext{
${ }^{5}$ Corte IDH. Caso Gudiel Álvarez y otros (Diario Militar) vs. Guatemala. Fondo, Reparaciones y Costas. Sentencia de 20 noviembre de 2012, Serie C, núm. 253, párr. 53.

${ }^{6}$ Corte IDH. Caso Contreras y otros vs. El Salvador. Fondo, Reparaciones y Costas. Sentencia de 31 de agosto de 2011. Serie C, núm. 232, párr. 135; Corte IDH. Caso Zambrano Vélez y otros vs. Ecuador. Fondo, Reparaciones y Costas. Sentencia de 4 de julio de 2007. Serie C No. 166, párr. 128; entre otros.
} 
Escalante, L. La memoria como derecho humano en Argentina: Una reconstrucción desde la teoría crítica. Derecho y Ciencias Sociales. Mayo -Octubre 2021. No 25 .Pgs 1-22 ISSN 1852-2971. Instituto de Cultura Jurídica y Maestría en Sociología Jurídica. Facultad de Ciencias Jurídicas y Sociales. Universidad Nacional de La Plata. Argentina.

El artículo 63.1 de la Convención Interamericana de Derechos Humanos regula el proceder de la Corte IDH respecto a las reparaciones, se basa en el derecho consuetudinario, es decir se justifica por ser una costumbre internacional que establece el deber de reparar por un hecho ilícito y se desprende de la responsabilidad internacional de los Estados. A lo largo del desarrollo de su jurisprudencia, la Corte ha entendido que la reparación no consiste solo en indemnizaciones pecuniarias, sino que se extiende a otras formas de reparar, como las garantías de no repetición.

En sus primeras sentencias, declaró que la propia sentencia constituía en sí misma una forma de reparación y satisfacción para el daño moral sufrido por las víctimas y sus familiares ${ }^{7}$. Sin embargo, con posterioridad incluyó en el caso 'Aloeboetoe y otros vs. Surinam’ del año 1991 medidas de satisfacción que consideran también a la sociedad en la que se generó el daño.

En el caso 'Aloeboetoe y otros vs. Surinam', la Corte sentenció con carácter de reparación al Estado de Surinam, además de las reparaciones pecuniarias, a reabrir la escuela $\mathrm{y}$ dotarla de personal docente y administrativo para que funcione permanentemente ${ }^{8} \mathrm{y}$; determinó el derecho de los familiares de conocer donde se encontraban los restos de las víctimas desaparecidas ${ }^{9}$.

Es así que mediante ese caso la Corte IDH ha reconocido medidas de reparación a toda la comunidad afectada como objetivo que la sociedad conozca y no olvide la violación perpetrada por el Estado y ha dejado en manifiesto lo importante de recordar los hechos del pasado para que no vuelvan a repetirse. En muchas de las sentencias la Corte utiliza el término "sociedad como un todo" para referir a que las medidas dispuestas no benefician solo a las víctimas y sus familiares ${ }^{10}$.

La Corte distinguió entre las dimensiones individual y colectiva (la denomina histórica) de la memoria en el caso Anzualdo Castro vs. Perú, al entender que:

"La propuesta del Estado de sustituir el acto de reconocimiento por el "Museo de la Memoria" no constituye una medida individual de satisfacción adecuada, si bien el Tribunal reconoce que ese tipo de iniciativas son significativas en atención a la recuperación y construcción de la memoria

\footnotetext{
${ }^{7}$ Corte IDH Caso Velázquez Rodriguez vs. Honduras Sent. 29 de julio de 1988: Reparaciones y Costas párr. 36.

${ }^{8}$ Corte IDH. Caso Aloeboetoe y otros Vs. Suriname, Sent. 10 Septiembre 1993: Reparaciones y Costas párr. 116 apt. 5.

${ }^{9}$ Corte IDH. Caso Aloeboetoe y otros Vs. Suriname, párr. 109.

${ }^{10}$ Corte IDH. Caso 19 comerciantes Vs. Colombia, Sent. 5 Julio 2004: Fondo, Reparaciones y Costas, párr. 259, y Caso Comunidad Moiwana Vs. Surinam, Sent. 15 Junio 2005: Excepciones preliminares, Fondo, Reparaciones y Costas, párr. 204.
} 
Escalante, L. La memoria como derecho humano en Argentina: Una reconstrucción desde la teoría crítica. Derecho y Ciencias Sociales. Mayo -Octubre 2021. No 25 .Pgs 1-22 ISSN 1852-2971. Instituto de Cultura Jurídica y Maestría en Sociología Jurídica. Facultad de Ciencias Jurídicas y Sociales. Universidad Nacional de La Plata. Argentina.

histórica de una sociedad. En razón de lo anterior, la Corte considera necesario que el Estado realice un acto público de reconocimiento de responsabilidad por la desaparición"11.

Entre las medidas de reparación, la Corte ha dispuesto el deber del Estado a pedir disculpas públicas por las violaciones a los derechos humanos cometidas por sus propios agentes. Con esta medida busca asegurar el reconocimiento, la difusión y la publicidad del hecho condenado, como así también resarcir el honor de las víctimas y evitar que los hechos vuelvan a repetirte ${ }^{12}$.

Por otra parte, algunas sentencias establecen a los fines de conmemorar y visibilizar a las víctimas denominar calles y centros educativos con sus nombres, con la intención de "que tengan como efecto la recuperación de la memoria de las víctimas, el reconocimiento de su dignidad, el consuelo de sus deudos" ${ }^{\prime 13}$.

Otras de las medidas de reparación ordenadas por la Corte IDH a los Estados consiste en la construcción de monumentos o memoriales que tornan "necesario que la elección del lugar en el cual se erija el monumento sea acordada entre el Estado y los familiares de las víctimas" $" 14$ y que esté destinado a "la rehabilitación de las víctimas sobrevivientes, a la lucha contra la impunidad, al reconocimiento público de la responsabilidad estatal en desagravio de las víctimas, a la preservación de la memoria de las víctimas ejecutadas en la masacre, a la preservación de la memoria colectiva"15.

Asimismo, como una de las maneras de evitar la repetición de las violaciones de los derechos humanos por parte del Estado, la Corte IDH establece como obligatoria la capacitación en materia de derechos humanos a las fuerzas de seguridad ${ }^{16}$.

Sin embargo, pese a que la Corte es consciente de ambas dimensiones de la memoria (individual y colectiva), lo cierto es que no proporciona pautas claras para explicar las relaciones entre ambas dimensiones de la memoria ni tampoco considera esta última explícitamente como derecho humano.

\footnotetext{
${ }^{11}$ Corte IDH. Caso Anzualda Castro Vs. Peru. Excepci6n Preliminar, Fondo, Reparaciones y Costas. Sentencia de 22 de septiembre de 2009. Serie C No. 202, párr. 200.

${ }^{12}$ CorteI DH. Caso Cantoral Benavides vs. Perú, Sent. 3 Diciembre 2001 Reparaciones y Costas párr. 53 y Caso Niños de la Calle (Villagran Morales y Otros) vs. Guatemala, Sent. 19 noviembre 1999: Reparaciones y Costas, párr. 84.

${ }^{13}$ Corte IDH. Caso los 19 Comerciantes vs. Colombia, Sent. 5 Julio 2004: Fondo, Reparaciones y Costas, párr. 244.

${ }^{14}$ Corte IDH. Caso 19 comerciantes vs. Colombia, Sent. 5 Julio 2004. Fondo, Reparaciones y Costas, párr. 273.

${ }^{15}$ Corte IDH. Caso Masacre Plan Sánchez vs. Guatemala, Sent. 19 Noviembre 2004, párr. 23.

16 Corte IDH. Caso Masacre Mapiripán Vs. Colombia, Sent. 15 Septiembre 2005: párr. 316; Caso Montero Aranguren y otros (Retén de Catia) Vs. Venezuela, Sent. 05 Julio 2006: Excepciones Preliminares, Fondo, Reparaciones y Costas, párr. 160; entre otros.
} 
Escalante, L. La memoria como derecho humano en Argentina: Una reconstrucción desde la teoría crítica. Derecho y Ciencias Sociales. Mayo -Octubre 2021. No 25 .Pgs 1-22 ISSN 1852-2971. Instituto de Cultura Jurídica y Maestría en Sociología Jurídica. Facultad de Ciencias Jurídicas y Sociales. Universidad Nacional de La Plata. Argentina.

\section{El derecho a la memoria en Argentina}

En Argentina, el deber de memoria y no olvido surge ante los crímenes de lesa humanidad y violaciones sistemáticas a los derechos humanos acontecidos durante la última dictadura militar (1976-1983). Pero éste deber se extiende también a otros hechos dramáticos acontecidos en éste período ${ }^{17}$ y a sucesos anteriores cronológicamente pero que son considerados gestores de la violencia estatal posterior ${ }^{18}$.

Ahora bien, en cuanto a la recepción del derecho a la memoria como derecho humano fundamental en nuestro país, lo cierto es que no se ha dictado una norma en particular que lo reconozca como tal. Sin embargo, se puede encontrar reconocido implícitamente en las políticas públicas adoptadas a lo largo de los últimos años para garantizarlo como así también en las sentencias de los Tribunales, entre ellos nuestra Corte Suprema de Justicia de la Nación.

Desde 1983 Argentina ha atravesado diversas etapas, la creación de la Comisión Nacional sobre la Desaparición de Personas (CONADEP) fue una de las primeras medidas tomadas a días de recuperar la democracia en 1983, fue esta comisión la que presentó el primer informe Nunca Más de la región que culminó con el Juicio a las Juntas Militares del año 1985.

Pero poco tiempo después comenzó un período que, basado en una pretendida reconciliación nacional, hizo hincapié en las nociones de olvido y perdón. En 1986 y 1987, bajo una gran presión militar, el gobierno del presidente Raúl Alfonsín dictó las leyes de obediencia debida y punto final que implicaron el cierre de la mayoría de las investigaciones en curso.

Durante el gobierno del presidente Carlos Menem, en una clara política de reconciliación que le permitiera profundizar el modelo económico neoliberal que proponía, se otorgaron los indultos, incluso a quienes jurídicamente no podían beneficiarse con esta medida -por no haber concluido sus procesos judiciales-, y se compensó a las víctimas a través de indemnizaciones conforme las recomendaciones de organismos internacionales.

A pesar de ello, durante los años noventa se intensificaron las presiones judiciales internacionales y a través de cortes europeas se investigó la responsabilidad de los militares argentinos en la desaparición de ciudadanos de esos países. Además, la demanda social no

\footnotetext{
${ }^{17}$ La Guerra de Malvinas tiene su propio feriado conmemorativo, el 2 de abril, establecido por la Ley $\mathrm{N}^{\circ}$ 25.370/00, y además se encuentra entre los contenidos curriculares obligatorios para todas las jurisdicciones incorporados por la Ley $\mathrm{N}^{\circ} 26.206 / 06$, en su artículo 92 inc. b.

${ }^{18}$ La Resolución $N^{\circ}$ 420/07 del Ministerio de Defensa puso en funcionamiento de un sitio de homenaje y recordación en el recinto de la Base Aeronaval Almirante Marcos A. Zar, en donde el 22 de agosto de 1972 fueron asesinados 16 presos políticos y otros 3 heridos de gravedad, hecho conocido como la "Masacre de Trelew". Se considera que éste hecho marcó un hito en la historia argentina, que constituyó la génesis del terrorismo de Estado en Argentina que encontró su máxima expresión después del golpe militar de 1976.
} 
Escalante, L. La memoria como derecho humano en Argentina: Una reconstrucción desde la teoría crítica. Derecho y Ciencias Sociales. Mayo -Octubre 2021. No 25 .Pgs 1-22 ISSN 1852-2971. Instituto de Cultura Jurídica y Maestría en Sociología Jurídica. Facultad de Ciencias Jurídicas y Sociales. Universidad Nacional de La Plata. Argentina.

cesó y en esta etapa mediante el reclamo de Abuelas de Plaza de Mayo en su intento de recuperar niños y niñas nacidos en cautiverio o secuestrados, se creó el banco de datos genéticos.

A comienzos del retorno de la democracia predominaba un relato dominante sobre el período dictatorial que enfatizaba la responsabilidad de dos sectores que se habían enfrentado, la dictadura y a quienes la habían enfrentado -entre ellos montoneros-. Esta versión es conocida como la 'teoría de los dos demonios' y si bien acusa a los jefes militares como ejecutores del terrorismo de estado y permite su juicio que contribuyó significativamente en la toma de conciencia pública sobre los crímenes cometidos durante la dictadura; coloca a la sociedad como mera espectadora del conflicto y fomenta la ignorancia del apoyo que en un primer momento un amplio sector dio a las fuerzas armadas, así como el rol activo de muchos sectores de la sociedad civil en la preparación y soporte al golpe militar.

Años después y ante los constantes reclamos por parte de los movimientos de derechos humanos en particular y de gran parte de la comunidad en general, bajo la administración de Néstor Kirchner los juicios contra los represores pudieron volver a reactivarse luego de que la Ley 25.779/03 derogara las Leyes de Punto Final y Obediencia Debida y los indultos. Finalmente, con la sentencia de la Corte Suprema de Justicia de la Nación en el caso 'Simón, Julio Héctor y otros’ del año 2005 se confirmó la decisión de inconstitucionalidad de las llamadas leyes de impunidad y la constitucionalidad de la Ley 25.779.

En ese contexto, una política de la memoria actuó como una "acción deliberada, establecida por los gobiernos o por otros actores políticos o sociales con el objetivo de conservar, transmitir y valorizar el recuerdo de determinados aspectos del pasado considerados particularmente significativos o importantes" (Groppo, 2002: 192).

Ahora bien, es importante en este punto para evitar sacralizaciones erróneas referir que las políticas públicas de memoria institucionalizan memorias hegemónicas, que seleccionan y marginan a aquellos grupos, memorias o acontecimientos contrarios, por lo que siempre están en disputa y es fundamental para su análisis conocer quiénes las implementan, cómo las llevan a cabo, con qué intenciones y cómo son recibidas por el resto de la sociedad. Sobre este punto, Jelin (2005) refiere que en la transición democrática si bien se abre espacio para la participación y las elecciones, lo cierto es que este discurso democrático se torna hegemónico, aunque en términos de memoria resulta imposible una visión e interpretación únicas del pasado.

Con relación al Presidente Kirchner, las políticas de memoria implementadas estuvieron marcadas por un trasfondo simbólico asociado a algunas fechas de la memoria en la búsqueda 
Escalante, L. La memoria como derecho humano en Argentina: Una reconstrucción desde la teoría crítica. Derecho y Ciencias Sociales. Mayo -Octubre 2021. No 25 .Pgs 1-22 ISSN 1852-2971. Instituto de Cultura Jurídica y Maestría en Sociología Jurídica. Facultad de Ciencias Jurídicas y Sociales. Universidad Nacional de La Plata. Argentina.

por conmemorar y mantener viva la reflexión sobre los acontecimientos producidos durante la última dictadura.

Mediante la Ley Nacional $N^{\circ}$ 26.085/06 se incorporó el 24 de marzo, instituido por la Ley $\mathrm{N}^{\mathrm{O}} 25.633$ como 'Día Nacional de la Memoria por la Verdad y la Justicia' en conmemoración de quienes resultaron víctimas del proceso iniciado en esa fecha del año 1976, entre los feriados nacionales. La Ley Nacional N²6.323/07 declaró al 10 de diciembre 'Día de la Restauración de la Democracia' y dispuso que sería celebrado en todo el territorio nacional, mediante actos pedagógicos y académicos que promuevan los valores democráticos, su significado histórico, político y social.

Las fechas conmemorativas, como toda marca o inscripción de la memoria, no se concretan simplemente una vez que se logra su incorporación a los calendarios educativos y públicos, sino que son apropiadas y resignificadas constantemente por los actores sociales de acuerdo a sus propias particularidades y circunstancias políticas (Jelin, 2004).

También hay que destacar el Archivo Nacional de la Memoria, creado en diciembre de 2013 por el decreto presidencial $\mathrm{n}^{\circ} 1259 / 03$, que tiene entre otras funciones la de preservar la documentación del Estado relacionada con las violaciones a los derechos humanos y está ubicado en un sitio especialmente simbólico: el ex centro clandestino de detención ex-ESMA.

El decreto hace referencia en sus considerandos a la voluntad del Estado de cumplir con las obligaciones internacionales asumidas en materia de derechos humanos y específicamente al derecho a la memoria relacionándolo con el derecho a la verdad no solo de las víctimas sino también de la sociedad en su conjunto y que conlleva el relativo deber de memoria del Estado (dimensión individual y colectiva respectivamente).

También se dictó la ley $\mathrm{N}^{\circ} 26.691$ de Sitios de la Memoria, cuyo objetivo es la preservación, señalización y difusión de "sitios de la memoria del terrorismo de Estado", entendidos como aquellos lugares que funcionaron como centros clandestinos de detención, tortura y exterminio o donde sucedieron hechos emblemáticos del accionar de la represión ilegal desarrollada durante el terrorismo de Estado ejercido en el país hasta el 10 de diciembre de 1983.

Durante ésta última etapa de reivindicación de la memoria, también se implementaron políticas públicas dirigidas hacia las fuerzas armadas que modificaron los planes de estudio e incorporaron en ellos el tema de los derechos humanos.

Mediante el Decreto N ${ }^{\circ} 788 / 07$ se creó la Dirección Nacional de Derechos Humanos (DDHH) y Derecho Internacional Humanitario (DIH) en la órbita de la Secretaría de Estrategia y Asuntos Militares, cuya responsabilidad primaria es instrumentar y difundir en el 
Escalante, L. La memoria como derecho humano en Argentina: Una reconstrucción desde la teoría crítica. Derecho y Ciencias Sociales. Mayo -Octubre 2021. No 25 .Pgs 1-22 ISSN 1852-2971. Instituto de Cultura Jurídica y Maestría en Sociología Jurídica. Facultad de Ciencias Jurídicas y Sociales. Universidad Nacional de La Plata. Argentina.

área de su competencia las normas del Derecho Internacional de los DH y del DIH con el objeto de afianzar el respeto y protección de los derechos esenciales de las personas, tanto en tiempos de paz como de conflicto.

Además, la Subsecretaría de Formación ha incorporado a los planes de estudio mediante la Resolución MD №872/07, las siguientes materias: Derecho Internacional Público, Derechos Humanos (DDHH), Derecho Internacional Humanitario (DIH) y Derecho Internacional de los Conflictos Armados (DICA); en una clara muestra de un intento de formar oficiales respetuosos de los derechos humanos y orientados al servicio público.

También, desde una dimensión pedagógica y de trasmisión de la memoria se puso en marcha el Programa Educación y Memoria del Ministerio de Educación en el año 2006, con el objetivo de consolidar una política educativa que promueva la enseñanza de la historia reciente mediante la elaboración y puesta a disposición de materiales y acciones de capacitación docente a nivel nacional, con el objetivo principal de transmitir a las generaciones futuras el pasado reciente, con una mirada crítica de los acontecimientos a través del trabajo coordinado entre docentes y alumnos. De esta manera, fomenta una pedagogía de la memoria que colabora en la trasmisión de las experiencias pasadas, intenta desarmar las condiciones que las hicieron posibles al acercarse a una de las posibles formas de 'garantía de no repetición' y recupera el acto de recodar como un imperativo categórico (Dussel, 2002; Raggio, 2007).

En muchos de los casos, estas políticas públicas de memoria -seleccionadas entre otras por resultar las más relevantes entre las conmemorativas, pedagógicas y de conservación documental ${ }^{19}$-, fueron experiencias adoptadas en respuesta a pedidos de la sociedad, con un rol clave de los organismos de derechos humanos y organizaciones de víctimas y familiares. En esta etapa, se dejó de utilizar los aciertos y errores de organizaciones populares para justificar el golpe militar y evitar la condena de sus responsables, la conocida 'teoría de los dos demonios'.

Luego de estas políticas públicas de memoria que cumplían los estándares internacionales establecidos por los 'Principios internacionales para la protección y la promoción de los Derechos Humanos, para la lucha contra la impunidad', los 'Principios sobre Políticas Públicas de Memoria en las Américas' y los lineamientos que se desprenden aunque no resulten sistemáticos de la jurisprudencia de la Corte IDH, en los últimos años se han producido retrocesos.

\footnotetext{
${ }^{19}$ Ver Garretón, F.; González, M.; y Lauzán, S. (2011) y Escalante, L. (2016) para un relevamiento completo de las políticas públicas de esta etapa.
} 
Escalante, L. La memoria como derecho humano en Argentina: Una reconstrucción desde la teoría crítica. Derecho y Ciencias Sociales. Mayo -Octubre 2021. No 25 .Pgs 1-22 ISSN 1852-2971. Instituto de Cultura Jurídica y Maestría en Sociología Jurídica. Facultad de Ciencias Jurídicas y Sociales. Universidad Nacional de La Plata. Argentina.

Con la nueva dirección política de Mauricio Macri, conforme lo relevado por el CELS (2017) tuvo lugar el desmantelamiento y debilitamiento de las políticas públicas en memoria. En enero de 2017 el Poder Ejecutivo decretó que el feriado nacional del 24 de marzo, 'Día de la Memoria por la Verdad y la Justicia', instaurado por la Ley Nacional № 26.085/2006, fuera movible, lo que suscitó las críticas de un amplio sector social, político y de las organizaciones de derechos humanos y finalmente, se devolvió una semana más tarde su inmovilidad mediante otro decreto presidencial.

El Poder Ejecutivo Nacional durante todo el año 2016 con el fin de reducir el empleo público en el ámbito de su competencia, debilitó distintos organismos en áreas específicamente diseñadas en el ámbito de promoción de los derechos humanos. En marzo de 2016 se disolvió la Dirección Nacional de Derechos Humanos del Ministerio de Seguridad que era la encargada de contestar requerimientos del poder judicial sobre el accionar de la fuerzas de seguridad durante la dictadura, de esa manera contribuía a la investigación y sanción de las violaciones a los derechos humanos.

En el ámbito de la Secretaría de Derechos Humanos en el que funciona el Centro de Asistencia a las Víctimas de Violaciones a los Derechos Humanos "Dr. Fernando Ullua" se ha visto afectado por los despidos. Por su parte, las autoridades ministeriales del nuevo gobierno abandonaron las consultas realizadas a la Dirección Nacional de Derechos Humanos y Derecho Internacional Humanitario que funciona en el Ministerio de Defensa tendientes a verificar que no se otorguen ascensos a personas vinculadas a violaciones de derechos humanos tanto durante la dictadura como en democracia.

La Dirección de Sitios de Memoria desde el cambio de gestión dejó de depender directamente de la Secretaría de Derechos Humanos y pasó a la órbita del Archivo de la Memoria, un organismo descentralizado, lo que presentó numerosas dificultades, entre ellas la conservación de los edificios ex centros clandestinos de detención, hoy sitios de la memoria.

En diciembre de 2016 el Gobierno presentó su Plan Nacional de Acción en Derechos Humanos 2017-2020 basado en cinco ejes temáticos: inclusión, no discriminación e igualdad; seguridad pública y no violencia; memoria, verdad, justicia y políticas reparatorias; acceso universal a derechos y cultura cívica y compromiso con los Derechos Humanos.

Respecto del eje "Memoria, Verdad y Justicia", los objetivos planteados consistían en garantizar los derechos a la memoria y a la verdad desde su acepción individual y colectiva y, promover el conjunto de medidas judiciales y políticas públicas, destinadas a investigar y 
Escalante, L. La memoria como derecho humano en Argentina: Una reconstrucción desde la teoría crítica. Derecho y Ciencias Sociales. Mayo -Octubre 2021. No 25 .Pgs 1-22 ISSN 1852-2971. Instituto de Cultura Jurídica y Maestría en Sociología Jurídica. Facultad de Ciencias Jurídicas y Sociales. Universidad Nacional de La Plata. Argentina.

sancionar a los responsables de las graves violaciones a los derechos humanos ${ }^{20}$. Sin embargo, en los hechos las políticas implementadas a tales fines fueron desmanteladas o debilitadas en esa gestión. Quedará analizar cuál será el rumbo que tomará el actual presidente Alberto Fernández durante su gestión.

Por otra parte, como adelantamos no hay una normativa que recepte expresamente el derecho a la memoria en nuestro país, sin embargo se han elaborado proyectos y anteproyectos de leyes en los últimos años. Si bien ninguna de estas iniciativas ha tenido acogida hasta el momento, lo cierto es que una Ley de Memoria Histórica o de Fortalecimiento y Protección de la Memoria, la Verdad y la Justicia, sería un componente complementario de las políticas públicas sobre derechos humanos llevadas adelante en los últimos años aunque inexplicablemente nunca fue aprobada por el Congreso.

Finalmente, en cuanto a la jurisprudencia de nuestro Tribunal superior, cabe referir que la Corte Suprema de Justicia de la Nación en la causa 'Yofre de Vaca Narvaja, Susana c/ Ministerio del Interior' (Expte. 443459/98) consideró que:

"la ley 24.043 tiene una finalidad reparadora de situaciones injustas, propias de la concepción absolutista y excluyente de todo el disenso que imperó en esa etapa, donde la persecución se extendió no sólo a la persona que se alzaba contra el régimen, sino a su familia, a sus bienes y hasta su memoria" (sent. del 14 de octubre de 2004. Fallos: 327:4241).

De esta manera la CSJN reconocía el derecho individual a la memoria de las víctimas que fueron privadas del derecho constitucional a la libertad, no en virtud de una orden de autoridad judicial competente, sino en razón de actos ilegítimos, emanados en ciertas circunstancias de tribunales militares o de quienes ejercían el Poder Ejecutivo de la Nación durante el último gobierno de facto.

Por su parte, la entonces Procuradora General de la Nación, Alejandra Gils Carbó, al presentar su dictamen ante la CSJN en la causa 'Gómez Miranda, Federico c/ Gaspari, Juan Alberto' (CSJ 48/2014(50 G)/CS1), refirió que las expresiones referidas a graves violaciones de derechos humanos revisten interés público pues ayudan a garantizar el derecho a la verdad e hizo referencia a la dimensión colectiva del derecho a la memoria:

"El debate amplio y desinhibido sobre esos acontecimientos tiene un valor instrumental para garantizar la dimensión colectiva del derecho a la verdad, memoria y justicia, que ha sido consagrado por los distintos sistemas de protección de derechos humanos (...)”21.

\footnotetext{
${ }^{20}$ Ver https://www.argentina.gob.ar/sites/default/files/plan_nacional_de_derechos_humanos_2018.pdf

${ }^{21}$ Ver http://www.mpf.gob.ar/dictamenes/2016/AGilsCarbo/abril/Gomez_CSJ_48_2014.pdf (p. 7).
} 
Escalante, L. La memoria como derecho humano en Argentina: Una reconstrucción desde la teoría crítica. Derecho y Ciencias Sociales. Mayo -Octubre 2021. No 25 .Pgs 1-22 ISSN 1852-2971. Instituto de Cultura Jurídica y Maestría en Sociología Jurídica. Facultad de Ciencias Jurídicas y Sociales. Universidad Nacional de La Plata. Argentina.

\section{Conclusiones}

Si se retoman las pregunta planteadas en la introducción, podemos concluir que si bien el Derecho a la Memoria no ha sido reconocido expresamente por los instrumentos internacionales, regionales ni la normativa nacional, en el presente trabajo se realizó una reconstrucción de sus aspectos centrales (dimensión individual y colectiva) a través de las disposiciones de la Organización de Naciones Unidad, la Organización de Estados Americanos y la jurisprudencia regional y nacional sobre los otros tres pilares de la justicia transicional -verdad, justicia y reparación-. Esta reconstrucción fue posible desde la teoría crítica de los derechos humanos asumida y el método dialéctico relacional que adopta, en tanto entiende a la realidad como una totalidad cuyas partes están íntimamente relacionadas y considera a los derechos humanos en su universalidad, indivisibilidad e interdependencia, lo que permite afirmar que el derecho a la memoria se constituye como presupuesto de los otros tres.

En nuestro país, su reconocimiento en términos jurídicos surge principalmente de las políticas públicas puestas en marcha y que son el resultado de procesos de luchas emancipatorios llevados adelante por la sociedad civil, que dan cuenta de su construcción social y como producto de las luchas de los movimientos sociales. Ahora bien, una Ley de Memoria Histórica, de Fortalecimiento y Protección de la Memoria, la Verdad y la Justicia o similar, sería un componente complementario de las políticas públicas de memoria llevadas adelante en los últimos años aunque inexplicablemente nunca fue aprobada por el Congreso.

Lejos de pretender concluir el debate que puede surgir en torno a las políticas públicas de memoria impulsadas por los actores sociales y el Estado o incluso casos específicos, este trabajo pretende constituirse en un aporte al estímulo de la producción de otras investigaciones que permitan orientar el análisis del Derecho a la Memoria en Argentina desde un teoría crítica en Derechos Humanos que da cuenta de las relaciones que presenta con los derechos a la verdad, justicia y obtener reparación, como así también de los múltiples debates, luchas y contradicciones que surgen por imponer determinados sentidos del pasado reciente.

\section{Referencias}

Adorno, T. (2001 [1972]). Epistemología y Ciencias Sociales. Madrid: Ediciones Cátedra.

Allier, E. (2015). América Latina: la denuncia y el elogio del pasado reciente, memorias confrontadas a través de algunos casos nacionales. Ciudad paz-ando, Vol. 8, No. 2.

Arias Marín, A. (2012). Teoría crítica y derechos humanos: hacia un concepto crítico de víctima. Nómadas. Critical Journal of Social and Juridical Sciences, Vol. 36, No. 4. 
Escalante, L. La memoria como derecho humano en Argentina: Una reconstrucción desde la teoría crítica. Derecho y Ciencias Sociales. Mayo -Octubre 2021. № 25 .Pgs 1-22 ISSN 1852-2971. Instituto de Cultura Jurídica y Maestría en Sociología Jurídica. Facultad de Ciencias Jurídicas y Sociales. Universidad Nacional de La Plata. Argentina.

Arias Marín, A. (2015). Tesis sobre una teoría crítica de los Derechos Humanos. Revista de filosofía open insight, Vol. 6, No. 9

Cabrera Suárez, L. A. (2012), El derecho a la memoria y su protección jurídica: avance de investigación. Pensamiento Jurídico, No. 36.

Dulitzky, A. (2017), La memoria en la jurisprudencia de la Corte Interamericana de Derechos Humanos. En Parra Vera, O. y otros (Ed.), La lucha por los Derechos Humanos Hoy. Valencia: Tirant lo Blanch.

Dussel, I. (2002). La educación y la memoria. Notas sobre la política de la transmisión. Revista Anclajes., Vol. VI, No. 6.

Dussel, E. (2006), Ética de la liberación en la edad de la globalización y de la exclusión. Madrid: Trotta.

Escalante, L. (2016), Argentina: políticas públicas en memoria (2003-2015). Revista Argumentos, No. 3.

Fraser, N. y Honneth, A. (2006). Redistribución o reconocimiento. Madrid: Morata

Gándara Carballido, M. (2019), Los derechos humanos en el siglo XXI: una mirada desde el pensamiento crítico. Ciudad Autónoma de Buenos Aires: CLACSO.

Garretón, F.; González, M.; y Lauzán, S. (2011), Estudio de Políticas Públicas de Verdad y Memoria en 7 países de América Latina. Centro de Derechos Humanos, Facultad de Derecho, Universidad de Chile, Santiago de Chile. Recuperado en http://libros.uchile.cl/379.

Gómez Isa, F. (Dir.) (2006), El derecho a la memoria. Zarautz: GizaEskubideak Derechos Humanos.

Groppo, B. (2002). Las políticas de la memoria. Revista Sociohistórica, No. 11-12.

Guglielmucci, A. (2013). La consagración de la memoria: una etnografía acerca de la institucionalización del recuerdo sobre los crímenes del terrorismo de Estado en la Argentina. Buenos Aires: Antropofagia.

Halbwachs, M. (2004 [1968]). La memoria colectiva. Zaragoza: Prensas Universitarias de Zaragoza

Harvey, David (2007). Espacios del Capital. Hacia una Geografía Crítica. Madrid: Akal.

Herrera Flores, J. (2005), Los derechos humanos como productos culturales. Crítica del humanismo abstracto. Madrid: Catarata.

Herrera Flores, J. (2008), La reinvención de los derechos humanos. Sevilla: Atrapasueños.

Honneth, A. (1997), La lucha por el reconocimiento. Barcelona: Crítica.

Horkheimer, M. (2003 [1974]), Teoría crítica. Buenos Aires: Amorrotu.

Jelin, E. (2004), Fechas de la memoria social. Las conmemoraciones en perspectiva comparada. Revista Íconos, No. 18.

Jelin, E. (2005), Exclusión, memorias y luchas políticas. En Mato, D. (2005) (Comp.), Cultura, políticas y sociedad. Perspectivas latinoamericanas. Buenos Aires: CLACSO.

Jelin, E. (2012), Los trabajos de la memoria. Lima: IEP.

Luther, J. (2010), El derecho a la memoria como derecho cultural del hombre en democracia. Revista Española de Derecho Constitucional, No. 89. 
Escalante, L. La memoria como derecho humano en Argentina: Una reconstrucción desde la teoría crítica. Derecho y Ciencias Sociales. Mayo -Octubre 2021. № 25 .Pgs 1-22 ISSN 1852-2971. Instituto de Cultura Jurídica y Maestría en Sociología Jurídica. Facultad de Ciencias Jurídicas y Sociales. Universidad Nacional de La Plata. Argentina.

Raggio, Sandra (2004). La enseñanza del pasado reciente. Hacer memoria y escribir la historia en el aula. Revista Clio \& Asociados, Vol. 5.

\section{Documentos e informes consultados}

CELS (2017), Informe sobre el proceso de Memoria, Verdad y Justicia en la Argentina. Recuperado en: https://www.cels.org.ar/web/wp-content/uploads/2017/05/Informeproceso-de-MVJ-2017.pdf

Comisión Interamericana de Derechos Humanos (2019), Principios sobre Políticas Públicas de Memoria en las Américas (Res. 3/2019). Recuperado en https://www.oas.org/es/cidh/decisiones/pdf/Resolucion-3-19-es.pdf

Organización de Naciones Unidas (1996), Estructura de principios y directivas fundamentales concernientes al derecho a reparación de las víctimas de violaciones flagrantes de los derechos humanos y del derecho humanitario (E/CN.4/Sub.2/1996/17). Recuperado en https://documents-ddsny.un.org/doc/UNDOC/GEN/G96/128/33/PDF/G9612833.pdf?OpenElement

Organización de Naciones Unidas (1997), Principios básicos para la protección y la promoción de los derechos humanos para la lucha contra la impunidad (E/CN. 4/Sub. 2/1997/20/Rev.1). Recuperado de http://www.derechos.org/nizkor/doc/joinete.html

Organización de Naciones Unidas (2005), Conjunto de principios actualizado para la protección y la promoción de los derechos humanos mediante la lucha contra la impunidad (E/CN.4/2005/102/Add.1). Recuperado de https://ap.ohchr.org/documents/dpage_s.aspx?si=E/cn.4/2005/102/Add.1

\section{Sentencias Corte IDH}

Corte IDH Caso 19 comerciantes Vs. Colombia, Sent. de 5 Julio de 2004: Fondo, Reparaciones $\quad$ y $\quad$ Costas. Recuperado en https://www.corteidh.or.cr/docs/casos/articulos/seriec_109_esp.pdf

Corte IDH Caso Aloeboetoe y otros Vs. Suriname, Sent. de 10 Septiembre de 1993: Reparaciones $\quad y \quad$ Costas. Recuperado de https://www.corteidh.or.cr/docs/casos/articulos/seriec_15_esp.pdf

Corte IDH. Caso Anzualda Castro Vs. Peru. Excepción Preliminar, Fondo, Reparaciones y Costas. Sent. de 22 de septiembre de 2009. Serie C No. 202. Recuperado en http://www.corteidh.or.cr/docs/casos/articulos/seriec_202_esp.pdf

Corte IDH. Baldeón García vs. Perú, Sent. de 6 de abril de 2006: Fondos, Reparaciones y Costas. Recuperado http://www.corteidh.or.cr/docs/casos/articulos/seriec_147_esp1.pdf

Corte IDH. Caso Bámaca Velázquez vs. Guatemala, Sent. de 22 de febrero de 2002: $\begin{array}{lllll}\text { Reparaciones } & \mathrm{y} \text { Costas. } & \text { Recuperado }\end{array}$ http://www.corteidh.or.cr/docs/casos/articulos/Seriec_91_esp.pdf

Corte IDH. Caso Cantoral Benavides vs. Perú Sent. de 3 Diciembre de 2001: Reparaciones y Costas. Recuperado http://www.corteidh.or.cr/docs/casos/articulos/Seriec_88_esp.pdf

Corte IDH Caso Comunidad Moiwana Vs. Surinam, Sent. de 15 Junio de 2005: Excepciones preliminares, Fondo, Reparaciones y Costas. Recuperado en https://www.corteidh.or.cr/docs/casos/articulos/seriec_124_esp1.pdf 
Escalante, L. La memoria como derecho humano en Argentina: Una reconstrucción desde la teoría crítica. Derecho y Ciencias Sociales. Mayo -Octubre 2021. № 25 .Pgs 1-22 ISSN 1852-2971. Instituto de Cultura Jurídica y Maestría en Sociología Jurídica. Facultad de Ciencias Jurídicas y Sociales. Universidad Nacional de La Plata. Argentina.

Corte IDH. Caso Contreras y otros vs. El Salvador. Fondo, Reparaciones y Costas. Sentencia de 31 de agosto de 2011. Serie C, núm. 232. Recuperado de http://www.corteidh.or.cr/docs/casos/articulos/seriec_232_esp.pdf

Corte IDH. Caso Gudiel Álvarez y otros (Diario Militar) vs. Guatemala. Fondo, Reparaciones y Costas. Sent. de 20 noviembre de 2012, Serie C, núm. 253. Recuperado de http://www.corteidh.or.cr/docs/casos/articulos/seriec_253_esp1.pdf

Corte IDH. Caso Masacre Ituango vs. Colombia, Sent. de 1 de julio de 2006. Recuperado en https://www.corteidh.or.cr/docs/casos/articulos/seriec_148_esp.pdf

Corte IDH. Caso Masacre Plan Sánchez vs. Guatemala, Sent. de 19 Noviembre de 2004: Fondo. Recuperado

en https://www.corteidh.or.cr/docs/casos/articulos/seriec_105_esp.pdf

Corte IDH. Caso Masacre Mapiripán Vs. Colombia, Sent. de 15 Septiembre de 2005. Recuperado en http://www.corteidh.or.cr/docs/casos/articulos/seriec_134_esp.pdf

Corte IDH. Caso Montero Aranguren y otros (Retén de Catia) Vs. Venezuela, Sent. de 5 Julio de 2006: Excepciones Preliminares, Fondo, Reparaciones y Costas. Recuperado en http://www.corteidh.or.cr/docs/casos/articulos/seriec_150_esp.pdf

Corte IDH. Caso Niños de la Calle (Villagran Morales y Otros) vs. Guatemala, Sent. de 19 noviembre de 1999: Reparaciones y Costas. Recuperado en https://www.corteidh.or.cr/docs/casos/articulos/Seriec_63 esp.pdf

Corte IDH. Trujillo Oroza vs. Bolivia, Sent. de 22 de febrero 2002: Reparaciones y Costas. Recuperado en: https://www.corteidh.or.cr/docs/casos/articulos/Seriec_92_esp.pdf

Corte IDH Caso Velázquez Rodriguez vs. Honduras. Sent. de 29 de julio de 1988: $\begin{array}{llll}\text { Reparaciones } & \text { y } & \text { Costas. Recuperado de }\end{array}$ http://www.corteidh.or.cr/docs/casos/articulos/seriec_04_esp.pdf

Corte IDH. Caso Zambrano Vélez y otros vs. Ecuador. Fondo, Reparaciones y Costas. Sent. de 4 de julio de 2007. Serie C No. 166. Recuperado de https://www.corteidh.or.cr/docs/casos/articulos/seriec_166_esp1.pdf 